\title{
The National Cancer Institute's Health Information National Trends Survey [HINTS]: a national cross- sectional analysis of talking to your doctor and other healthcare providers for health information
}

\author{
Julie E Volkman ${ }^{1,2^{*}}$, Tana M Luger ${ }^{1}$, Kimberly LL Harvey ${ }^{1,2}$, Timothy P Hogan ${ }^{1,2}$, Stephanie L Shimada ${ }^{1,2,3}$, \\ Daniel Amante ${ }^{2}$, D Keith Mclnnes ${ }^{1,3}$, Hua Feng ${ }^{1,2}$ and Thomas K Houston ${ }^{1,2}$
}

\begin{abstract}
Background: The need to understand preferred sources of health information remains important to providing patient-centered care. The Internet remains a popular resource for health information, but more traditional sources may still be valid for patients during a recent health need. This study sought to understand the characteristics of patients that turn to their doctor or healthcare provider first for a recent health or medical information need.

Methods: Using the national cross-sectional survey, Health Information National Trend Study [HINTS], characteristics of those who sought a doctor or healthcare provider for a recent health information need were compared to other sources. Weighted survey responses from Cycle 1 and Cycle 2 of the HINTS survey were used for multivariable logistic regression.

Results: A total 5,307 patient responses were analyzed. Overall, those who seek a doctor or healthcare provider first for a health need are female, 46-64 years, White non-Hispanic, educated, in good health and users of the Internet. Yet, adjusted logistic regressions showed that those who sought a doctor or healthcare provider first during a recent health information need compared to other sources were most likely to be $65+$ years, in poor health, less educated and have health insurance.
\end{abstract}

Conclusions: Patients who seek their doctor or healthcare provider first for health information rather than other sources of information represent a unique population. Doctors or healthcare providers remain an important resource for these patients during recent needs, despite the wide use of the Internet as a source of health information.

Keywords: Health information needs, Sources for health information, Doctor-patient communication, National cross-sectional survey

\section{Background}

Health information access for patients is a key facet of the provision of patient-centered care [1]. Patients require appropriate health information in order to participate in treatment decisions and increase communication with their doctor or healthcare provider [1-5]. Doctors and healthcare providers recognize the importance of sources of health information, as improved patient access

\footnotetext{
*Correspondence: julie.volkman@va.gov

'eHealth Quality Enhancement Research Initiative, US Department of

Veterans Affairs, 200 Springs Road, Bedford, MA 01730, USA

${ }^{2}$ University of Massachusetts Medical School, 368 Plantation Street,

Worcester, MA 01605, USA

Full list of author information is available at the end of the article
}

may increase patient satisfaction with care and lead to better health outcomes and self-management $[4,6]$. Doctors and healthcare providers have devoted time and resources to help understand patients' health information needs and appropriate resources for them [6] to support patient chronic disease management [7] and to understand the value of different sources of health information for patients.

For several years, the Internet has become a frequent resource for health-related information for patients and their caregivers. In 2012, the Pew Internet \& American Life Project reported $81 \%$ of U.S. adults use the Internet, and $72 \%$ said they have looked online for health information in the past 12 months [8]. Online health information 
is often sought by women more frequently than men, by more non-Hispanic Whites/Caucasians compared to Hispanics and African-Americans, more often by those with higher incomes and higher education levels, and by those who are employed [9-11]. Yet, the Internet does not remain the sole source of health information for patients. When asked to consider their last serious health issue and source of health information, either online or offline, $40 \%$ of U.S. adults surveyed in 2012 reported receiving information, care, or support from a doctor or other healthcare provider [8]. Additionally, patients traditionally trust their doctor or healthcare provider as a source of information, compared to other communication channels [12], and patients tend to solicit family, friends, or co-workers as reliable sources of information [13]. For example, racial minority groups tend to trust friends and family members for health information [14], and older adults prefer to rely on social sources of information as well [15]. Thus, in spite of its popularity, the Internet may not be the only resource for some patients when seeking health information. Understanding these preferences for patients is important for providing patient-centered care [1].

While the Internet remains a viable source of health information, it is clear that individuals have not completely eliminated more traditional approaches to information acquisition. We wished to gain insight into the health information habits of patients by understanding characteristics of patients turning towards a doctor or healthcare provider first when confronted with a recent health or medical information need. We analyzed responses to a national cross-sectional survey, the Health Information National Trend Survey (HINTS) sponsored by the National Cancer Institute, to understand where patients would turn to first during a recent medical need and the significant characteristics of individuals turning to a doctor or healthcare provider first compared to other information sources.

\section{Method}

\section{Study design, sample and data collection}

Data for our analyses were from the National Cancer Institute's Health Information National Trends Survey (HINTS 2011-2013) (hints.cancer.gov), a national crosssectional survey of the U.S. adult population (ages 18 years and older) assessing how individuals find, use and understand health information. Data were collected in two cycles: a) Cycle 1 from October 2011 to February $2012(\mathrm{n}=3959)$ and Cycle 2 from October 2012 through January $2013(\mathrm{n}=3630)$. Both cycles were administered through mailed questionnaires. The sample design for HINTS 2011-2013 was a two-stage, stratified sample. In the first stage, a stratified sample of addresses was selected from a file of residential addresses. In the second-stage, one adult was selected within each sampled household using one of two randomly assigned respondent selection conditions where either the adult with the next birthday or all adults within the household completed a questionnaire. The sampling frame consisted of a database of addresses used by Marketing Systems Group (MSG) to provide random samples of addresses [16]. The response rate for Cycle 1 was $36.7 \%$ and for Cycle 2 was 39.97\% [16]. Extensive details on the study design, methods and sampling plan of HINTS have been published elsewhere $[17,18]$.

\section{Participants}

Combined data for HINTS 2011-2013 Cycle 1 and Cycle 2 resulted in a total of 7,589 individual respondents. Participants were included in the analyses if they were 18 years of age or older, had been asked about their most recent time seeking information about health or medical topics, and had provided any response to the question of interest $(\mathrm{N}=5,307)$. We did not include in the analysis missing responses $(n=33)$, erroneous responses $(n=965)$ or responses for whom the question was not ascertained $(n=1,284)$.

\section{Measures}

The HINTS survey includes 11 sections (A-K) across 125 questions. Sections include inquiries about looking for health information; using the Internet to find health information; health care; health, nutrition and physical activity; women and cancer; screening for cancer; beliefs about cancer; cancer history; looking for information about food and medical products; medical research and medical records; and household information.

Sources for a recent health information need was asked with the following question: "The most recent time you looked for information about health or medical topics, where did you go first?" Responses to this item $(n=5,307)$ were coded to create a dichotomous, dependent variable of "doctor or healthcare provider first" and "other sources" (books, brochures and pamphlets, cancer organization, family, friend/co-worker, Internet, library, magazines, newspapers, telephone information number, complementary, alternative or unconventional practitioner and all other specified sources). Questions were not asked related to the nature of the medical or health information need (see Additional file 1 for full HINTS survey).

Sociodemographic characteristics were assessed by inclusion of the following variables: age, gender, rural status, income, cancer history, general health, race/ ethnicity, education, health insurance, Veteran status and Internet use and access to the Internet.

Age was categorized as $18-45 ; 46-64 ; 65-75$; and 76-99 years according to the age distribution of respondents. Rural status was established using Census data as being completely rural or less than 2,500 urban 
population, adjacent or not adjacent to a metro area. Income level was derived from reported household pre-tax earnings from all sources within the past year and categorized as less than $\$ 20,000, \$ 20,000$ to less than $\$ 50,000$ and equal to or greater than $\$ 50,000$. Dichotomous cancer history was assessed with "Have you ever been diagnosed as having cancer?" General health status was measured with "In general, you would say your health is?" along the responses of Excellent, Very Good, Good, Fair and Poor. Race/ethnicity was categorized as non-Hispanic White, non-Hispanic black, Hispanic and all remaining responses collapsed as "other." Health insurance was categorized as having indicated healthcare coverage (not including dental or vision) through an employer, purchased privately through an insurance company, Medicare/Medicaid or other government program, VA, Tricare, IHS or any other specified source. The derived variable of Veteran status was determined by those who responded as having ever served on active duty in the U.S. armed forces, military reserves or national guard and/or positive response to having ever received or enrolled for healthcare or medical services at the VA or having TRICARE or other military healthcare insurance coverage. Internet use was categorized as having a positive response to the item "Do you ever go on-line to access the Internet or World Wide Web, or to send/receive email?" Access to the Internet was assessed as dial-up telephone lines, broadband (DSL, cable or FIOS), cellular network (phone, 3G/4G) and/or wireless network (Wi-Fi). Access to other sources of health information was not asked in the survey (see Additional file 1).

\section{Analysis}

Given the complex survey design of the HINTS study for both Cycles 1 and 2, we conducted a weighted analysis using procedures for analyzing sample survey data in SAS version 9.3 in order to calculate accurate population and subpopulation parameter estimates and confidence intervals for the U.S. adult population. We computed descriptive statistics including means and totals. Jackknife weights, provided by HINTS $[17,18]$, were used for calculating standard errors. Multivariable logistic regression analysis was used to examine the association of first-sought health information sources with key sociodemographic characteristics. We used a cutoff of $p<0.05$ to determine statistical significance for all analyses. The secondary analysis approved by the Department of Veterans Affairs Research and Development Committee.

\section{Results}

Overall, health information seekers reported most frequently going first to the Internet $(67.63 \%)$, followed by a doctor or healthcare provider first (15.66\%), publications (books, brochures, magazines and newspapers) first
(9.39\%), and family/friends/co-workers first (4.95\%) (See Table 1).

Those who sought a doctor or healthcare provider first for a recent health information need were female (53.81\%), 46-64 years (34.66\%), were non-Hispanic White (58.93\%), earned $\$ 50,000$ and above annually (34.14\%), had some college education (31.83\%) and more than college education (20.39\%), had health insurance $(85.86 \%)$ and were not a Veteran (80.64\%). The majority did not live in rural areas (97.68\%), did not have a cancer history $(86.12 \%)$, and reported having very good $(31.08 \%)$ to good (34.63\%) general health. More than half $(61.81 \%)$ currently used the Internet and accessed it through Broadband (64.29\%), although it was not their "first sought" health source for a recent medical need (See Table 2).

Differences did emerge in the characteristics of those who sought a doctor or healthcare provider first for a recent health information need compared to individuals that cited other source options (e.g., Internet, books, friends/family/co-workers, etc.) as their first choice. Results from the adjusted logistic regression showed that those who sought a doctor or healthcare provider first were most likely to be $65-75$ years $[\mathrm{OR}=3.05(95 \%$ CI, 2.13-4.35), $\mathrm{p}=.0001)$ and $75-99$ years $[\mathrm{OR}=2.88(95 \%$ $\mathrm{CI}, 1.89-4.38), \mathrm{p}=.006]$, less likely to have good health $[\mathrm{OR}=.88(95 \% \mathrm{CI}=.53-1.47), \mathrm{p}=.03]$ and more likely to be in poor health [OR $=3.99$ (95\% CI, .80-20.02), $\mathrm{p}=.05$ ], less likely to be a college graduate or more $[\mathrm{OR}=0.35$ (95\% CI, 0.17-0.75), $\mathrm{p}=.0009$ ], more likely to have health insurance $[\mathrm{OR}=1.72$ (95\% CI,1.03-2.88), $\mathrm{p}=.04]$, and less likely to use the Internet $[\mathrm{OR}=0.40$ (95\% CI, 0.29-0.56), $\mathrm{p}<.0001$ ] compared to those who sought other sources of information first during a recent health need (e.g., Internet, books, friends/family/co-workers, etc.). Gender and rural status did not significantly differ between doctor or healthcare provider first seekers and seekers of other sources (See Table 3). Unadjusted differences for cancer

Table 1 First health information source $(N=5,307)$

\begin{tabular}{lccc}
\hline Source & $\mathbf{N}$ & Weighted \% & $\mathbf{9 5 \%} \mathbf{~ C l}$ \\
\hline Internet & 3,315 & 67.63 & $65.88-69.38$ \\
Doctor or healthcare provider & 937 & 15.66 & $13.96-17.36$ \\
$\begin{array}{l}\text { Publications (books, } \\
\text { pamphlets, brochures, }\end{array}$ & 652 & 9.39 & $8.35-10.43$ \\
magazines and newspapers) & & & \\
Family/friends/co-workers & 235 & 4.95 & $4.03-5.87$ \\
Other & 72 & 0.99 & $0.58-1.39$ \\
Telephone Service & 40 & 0.61 & $0.34-0.89$ \\
Cancer Organization & 17 & 0.26 & $0.08-0.44$ \\
Library & 21 & 0.23 & $0.09-0.37$ \\
Complementary or alternative & 18 & 0.28 & $0.12-0.43$ \\
medicine practitioner & & & \\
\hline
\end{tabular}

Missing $=857$. 
Table 2 Characteristics health information seekers choosing doctor or healthcare provider first $(n=937)$

\begin{tabular}{|c|c|c|c|c|c|c|c|}
\hline \multirow[b]{2}{*}{ Gender } & \multirow[t]{2}{*}{$\mathrm{N}$} & \multirow[t]{2}{*}{ Weighted \% } & \multirow[t]{2}{*}{$95 \% \mathrm{Cl}$} & \multicolumn{4}{|c|}{ (Continued) } \\
\hline & & & & Health insurance & & & \\
\hline Male & 385 & 43.16 & $38.61-47.71$ & Yes & 853 & 85.86 & $81.56-90.15$ \\
\hline Female & 531 & 53.81 & $49.38-58.23$ & No & 69 & 13.02 & $8.83-17.21$ \\
\hline Missing & 21 & 3.03 & $0.47-5.58$ & Missing & 15 & 1.12 & $0.41-1.84$ \\
\hline Age & & & & Veteran status & & & \\
\hline $18-45$ & 150 & 28.62 & $23.12-34.13$ & Veteran & 139 & 11.45 & $8.87-14.02$ \\
\hline $46-64$ & 347 & 34.66 & $30.02-39.31$ & Non-Veteran & 735 & 80.64 & $77.11-84.17$ \\
\hline $65-75$ & 241 & 18.14 & $15.31-20.97$ & Missing & 63 & 7.91 & $4.84-10.99$ \\
\hline $76-99$ & 179 & 14.71 & $12.17-17.24$ & Internet use & & & \\
\hline Missing & 20 & 3.87 & $0-8.13$ & Yes & 550 & 61.81 & $57.11-66.50$ \\
\hline Rurality & & & & No & 386 & 38.17 & $33.48-42.85$ \\
\hline Yes (8-9) & 21 & 2.32 & $1.11-3.53$ & Missing & 1 & 0.03 & $0.00-0.08$ \\
\hline No $(1-7)$ & 916 & 97.68 & $96.47-98.89$ & Access to internet & & & \\
\hline Missing & $\sim$ & $\sim$ & $\sim$ & Telephone line & 52 & 5.09 & $2.67-7.53$ \\
\hline Cancer history & & & & Broadband (DSL, cable, or FIOS) & 359 & 37.47 & $32.33-42.61$ \\
\hline Yes & 186 & 13.50 & $11.25-15.74$ & Cellular network (phone, 3G/4G) & 166 & 22.29 & $16.53-28.04$ \\
\hline No & 746 & 86.12 & $83.83-88.40$ & Wireless network (Wi-Fi) & 274 & 31.30 & $26.00-36.60$ \\
\hline Missing & 5 & .39 & $0-0.78$ & Missing & 12 & 5.12 & $0.00-10.84$ \\
\hline
\end{tabular}

General health

Excellent

Very good

Good

Fair

Poor

Missing

Income

Less than and $\$ 20,000$

$\$ 20,000$ to $\$ 49,999$

$\$ 50 \mathrm{k}$ or above

Missing

Race/Ethnicity

White, $\mathrm{NH}$

African-American, $\mathrm{NH}$

Hispanic

Other, NH

Missing

Education

Less than high School

High school graduate

Some college

College or above

Missing

$\begin{array}{cc}8.71 & 5.77-11.64 \\ 31.08 & 26.47-35.68 \\ 34.63 & 30.00-39.25 \\ 16.47 & 12.70-20.24 \\ 6.48 & 2.81-10.15 \\ 2.64 & 1.36-3.92\end{array}$

$234 \quad 26.40$

$258 \quad 27.10$

$311 \quad 34.14$

$134 \quad 12.35$
Table 2 Characteristics health information seekers (Continued)

history, income, race, and veteran status were mitigated in the adjusted model. Stratifying the sample by Internet use did not yield different results regarding significant characteristics or significant interactions among the variables of interest.

\section{Discussion}

Overview of main findings

Understanding sources of health information is important given the prevalence of health information available online, and the implications of using online health information on health behaviors and health outcomes related to patient activation, health misinformation, and more. Results from our study suggest seeking information from a doctor or healthcare provider is a "not-so-close second" behind the Internet for health or medical information needs. Compared to other sources of health information, doctors and other healthcare providers still represent an important, trusted group for health or medical information, in particular for older patients, those with less education, patients who have health insurance and those who perceive themselves as being in poor health. Interestingly, those who turn to their doctor first were still Internet users in general, but chose to solicit a doctor or healthcare provider for health information instead of the Internet for a recent health or medical need. Doctors and healthcare providers thus still represent a very viable source of information for patients, specifically for a unique population. choosing doctor or healthcare provider first $(n=937)$ 
Table 3 Characteristics of health information seekers choosing doctor or healthcare provider first $(n=937)$ compared to other sources (Total $\mathrm{N}=4,370$ )

\begin{tabular}{|c|c|c|c|c|}
\hline & $\begin{array}{c}\text { Doctor or healthcare provider first } \\
\text { N (weighted \%) }\end{array}$ & $\begin{array}{l}\text { Other sources } \\
\mathrm{N} \text { (weighted \%) }\end{array}$ & $\begin{array}{l}\text { Unadjusted OR }(95 \% \mathrm{Cl}) \\
\text { p-value }\end{array}$ & $\begin{array}{l}\text { Adjusted OR }(95 \% \mathrm{Cl}) \text {, } \\
\text { p-value }\end{array}$ \\
\hline \multicolumn{5}{|l|}{ Gender } \\
\hline Male & 385 (14.94) & $1,592(85.06)$ & $1.00-$ & $1.00-$ \\
\hline Female & $531(15.93)$ & 2,695 (84.07) & $0.93(0.75-1.15), p=.47$ & $1.00(0.71-1.39), p=.98$ \\
\hline \multicolumn{5}{|l|}{ Age } \\
\hline $18-45$ & $150(9.41)$ & 1,541 (90.59) & $1.00-$ & $1.00-$ \\
\hline $46-64$ & $347(15.52)$ & $1,880(84.48)$ & $1.77(1.30-2.41), \mathrm{p}<.0001$ & $1.74(1.28-2.36), p=.18$ \\
\hline $65-75$ & $241(29.23)$ & $601(70.77)$ & $3.98(3.01-5.25), p<.0001$ & $3.05(2.13-4.35), p=.0001$ \\
\hline 76-99 & $179(40.76)$ & $262(59.24)$ & $6.63(4.72-9.31), p<.0001$ & $2.88(1.89-4.38), p=.006$ \\
\hline \multicolumn{5}{|l|}{ Rurality } \\
\hline No & $916(15.55)$ & $4,301(84.45)$ & $1.00-$ & $1.00-$ \\
\hline Yes & $21(22.38)$ & $69(77.62)$ & $1.57(0.86-2.86), p=.15$ & $1.20(0.46-3.13), p=.71$ \\
\hline \multicolumn{5}{|l|}{ Cancer history } \\
\hline No & $746(14.72)$ & $3,816(85.28)$ & $1.00-$ & $1.00-$ \\
\hline Yes & $186(25.98)$ & $535(74.02)$ & $2.03(1.63-2.53), p<.0001$ & $1.21(0.91-1.62), p=.19$ \\
\hline \multicolumn{5}{|l|}{ General health } \\
\hline Excellent & $71(11.59)$ & $558(88.41)$ & $1.00-$ & $1.00-$ \\
\hline Very good & $302(12.85)$ & $1,630(87.15)$ & $1.13(0.72-1.75), p<.0001$ & $0.95(0.59-1.54), p=.08$ \\
\hline Good & 347 (15.78) & $1,526(84.22)$ & $1.43(0.94-2.18), p=.02$ & $0.88(0.53-1.47), p=.03$ \\
\hline Fair & $141(21.69)$ & $497(78.31)$ & $2.11(1.33-3.36), p=.26$ & $0.98(0.55-1.73), p=.24$ \\
\hline Poor & $52(43.23)$ & $90(56.77)$ & $5.81(2.31-14.64), p=.0002$ & $3.99(0.80-20.02), p=.05$ \\
\hline \multicolumn{5}{|l|}{ Income } \\
\hline Less than $\$ 20,000$ & $234(22.57)$ & $692(77.43)$ & $1.00-$ & $1.00-$ \\
\hline$\$ 20,000$ to $\$ 49,999$ & $258(16.33)$ & $1,149(83.67)$ & $0.67(0.47-0.96), p=.95$ & $0.89(0.59-1.33), p=.73$ \\
\hline$\$ 50,000$ and above & $311(11.41)$ & $2,116(88.59)$ & $0.44(0.33-0.60), p<.0001$ & $0.87(0.55-1.36), p=.63$ \\
\hline \multicolumn{5}{|l|}{ Race } \\
\hline Non-Hispanic White & $532(13.93)$ & $2,812(86.07)$ & $1.00-$ & $1.00-$ \\
\hline Non-Hispanic Black & $143(15.04)$ & $581(84.96)$ & $1.09(0.81-1.48), p=.53$ & $1.11(0.75-1.64), p=.69$ \\
\hline Hispanic & $111(21.27)$ & $461(78.73)$ & $1.67(1.12-2.48), p=.04$ & $1.25(0.79-1.97), p=.81$ \\
\hline Other & $63(15.35)$ & $271(84.65)$ & $1.12(0.65-1.93), p=.75$ & $1.45(0.70-3.02), p=.48$ \\
\hline \multicolumn{5}{|l|}{ Education } \\
\hline Less than High School & $118(37.56)$ & $218(62.44)$ & $1.00-$ & $1.00-$ \\
\hline High School Graduate & $240(19.92)$ & $689(80.08)$ & $0.41(0.25-0.68), p=.29$ & $0.63(0.33-1.23), p=.51$ \\
\hline Some College & $292(13.99)$ & $1,318(86.01)$ & $0.27(0.17-0.44), p=.002$ & $0.52(0.26-1.05), p=.35$ \\
\hline College Grad. or More & $266(9.11)$ & $2,071(90.89)$ & $0.17(0.11-0.26), p<.0001$ & $0.35(0.17-0.75), p=.0009$ \\
\hline \multicolumn{5}{|l|}{ Health insurance } \\
\hline No & $69(12.01)$ & $563(87.99)$ & $1.00-$ & $1.00-$ \\
\hline Yes & $853(16.34)$ & 3,767 (83.66) & $1.43(0.96-2.13), p=.07$ & $1.72(1.03-2.88), p=.04$ \\
\hline \multicolumn{5}{|l|}{ Veteran status } \\
\hline Non-Veteran & 735 (14.43) & $3,780(85.57)$ & $1.00-$ & $1.00-$ \\
\hline Veteran & 139 (19.48) & 459 (80.52) & $1.44(1.06-1.94), p=.02$ & $1.04(0.72-1.49), p=.84$ \\
\hline
\end{tabular}




\begin{tabular}{|c|c|c|c|c|}
\hline \multicolumn{5}{|c|}{ Internet use } \\
\hline No & $386(42.35)$ & $547(57.65)$ & $1.00-$ & $1.00-$ \\
\hline Yes & $550(11.27)$ & 3,823 (88.73) & $0.17(0.14-0.22), p<.0001$ & $0.40(0.29-0.56), p<.0001$ \\
\hline
\end{tabular}

Note: Significant relationships are bolded.

$\mathrm{OR}=$ Odds ratio; $95 \% \mathrm{Cl}=$ Confidence Interval.

\section{Comparison with existing literature}

The HINTS analyses contrast with other studies which have found gender differences in the use of the Internet for health information as well as income-based, racial, and geographic differences [19] in access to the Internet $[8,10,11,20]$. In particular, Pew Internet and American Life Survey [8], using a smaller sample size of 3,014 adults living in the U. S., found that women, adults over 50 years old, non-Hispanic whites, and those with some college were more likely to get information from a physician when experiencing "a serious health issue or significant change in your health." Interestingly, these characteristics are comparable to the initial characteristics of our population from our findings. Yet, the Pew questions concern a more specific, serious health issue compared to the HINTS questionnaire which assesses a recent health or medical need. It is possible that gender and racial differences are found when health information is needed for a substantial reason, but age and education are more powerful predictors of a preference to rely on a physician first for general health information. For example, older adults and those who are less educated tend to prefer to be less involved overall in medical decisions [21], which could lend itself to relying on "expert" physicians for general health information.

Furthermore, patients who reported going to their doctor or health care provider first for a recent health information need were most frequently over 65 years old. Older adults are more likely to have complex medical profiles including multiple co-morbidities [22], making it necessary to synthesize health information about a variety of conditions. Consequently, a doctor or healthcare provider may be a first resource for health information needs as they are familiar with the complexities of multiple conditions. In addition, less educational attainment has been shown to be associated with more self-reported health information needs [23], making relying on the physician's expertise perhaps more appealing in order to acquire the desired information. Health literacy [24] may also be a driving factor in the relationship between education and health information needs. Health literacy concerns a patient's ability to acquire and understand health information [24] and is associated with lower educational attainment $[25,26]$. Thus, those with less education may have difficulty acquiring and processing information from other sources, preferring instead to rely on their physician. However, it is unclear how long HINTS respondents may have been seeing their doctor or healthcare provider for specific conditions or their health literacy level, which may have influenced the results for this sub-sample of individuals. Finally, those with health insurance were more likely to solicit information from a physician, suggesting that information from a doctor or healthcare provider may be a convenient and viable option.

Considering the differences by age, education and insurance, our results offer unique implications for those that did not select a doctor or healthcare provider as their first choice as a source during a recent health need. While our results are cross-sectional and causation cannot be inferred, it does offer suggestions about how online sources and other social sources (friends, family, co-workers, etc.) may affect the traditional information relationships between patients and their doctors and healthcare providers. For those younger, more educated, uninsured individuals that selected the Internet or other social sources, there may be concerns about the quality and accuracy of the information they find $[27,28]$, in addition to how they assimilate the information. Potentially, this information, if misinterpreted through communication outside of the patient-healthcare provider relationship or due to the complexities of multiple conditions, may put patients at risk.

\section{Strengths and limitations}

HINTS draws its strength from a reliance on multiple methods in order to reduce non-response [29], which was typical of a postal survey. The selected sample was sent an initial mailing of the questionnaire, a reminder card, and up to three additional questionnaire mailings. This also improved response rates from previous telephone administered waves of the HINTS survey. In addition, our analyses use the HINTS-recommended weights in order to adjust for non-response and provide more accurate parameter estimates. Nevertheless, our findings are not without limitations. The HINTS survey did not include information about the types of health information sought, which prevents us from probing if patients rely more on their physician for specific types of information regarding their conditions or other health needs. Additionally, we do not have knowledge of the type of doctor or healthcare 
provider, or length of the relationship, which could be significant influences regarding choice. Second, while we attempted to utilize rurality and type of Internet access as indicators of access to information, these may not reflect the true availability of health information to responders or their ability to process said information. Finally, health literacy was not assessed in the HINTS survey which could provide further explanation for group differences. Despite these limitations, the results do offer suggestions for future research and implications for sources for health information.

\section{Future research}

Participants in the HINTS survey may represent a unique sample of information-seekers as our lack of findings for income or racial differences might indicate. Further exploration of a preference for physician-provided health information in additional national samples for both serious and general health information needs may identify other significant factors. In addition, health literacy is likely an important construct which affects a preference for doctor-provided information. Future work will want to examine patient preferences for information across health literacy abilities in order to disentangle patients who avoid conducting their own health information searches rather than those who prefer to rely on the expertise of their physician regardless of their literacy level. With the recent initiation of the Patient Protection and Affordable Care Act in 2010 [30], additional research may want to see how changes in insurance regulations may change patient patterns in preferred sources of information. Finally, providing appropriate, effective health information depends on the particular patient's needs. Recent movements in developing patient-reported outcome measures such as the NIH's PROMIS [31] can provide physicians with standardized patient information which may help physicians to tailor health information provision for patients. Investigations into how patient-reported outcomes might inform the type and volume of information that patients require from physicians will be important.

\section{Conclusions}

The changing healthcare landscape makes it important to understand the needs of patients regarding their health information needs and sources of information. This study found that older, less educated patients with health insurance were more likely to rely on doctors or healthcare providers as a reliable source for health and medical topics. Older, less educated patients may require more information provision during face-to-face visits, as they may not desire to seek additional information via online or other sources. Continuing education training in patientcentered communication [32], which involves health information provision based upon the patient's needs and values and increasing patient-provider trust, may also support doctors and healthcare providers in giving effective health information to these patients in order to achieve optimal outcomes.

\section{Additional file}

Additional file 1: Health Information National Trends Survey.

\section{Competing interests}

The authors declare that they have no competing interests.

\section{Authors' contributions}

$\mathrm{JV}$ and TKH conceived of the study, participated in the coordination of analyses and drafted the manuscript. TL participated in the draft of the manuscript and an interpretation of the results. KLLH analyzed the results and participated in the draft of the manuscript. TPH, SLS, DKM, DA and HF made substantial contributions to the conception and design of the analyses, acquisition of the data and interpretation of the data. All authors read and approved the final manuscript.

\section{Acknowledgements}

This material is the result of work supported with resources and the use of facilities at the U.S. Department of Veterans Affairs, eHealth Quality Enhancement Research Initiative (QUERI) EHQ 10-190 at the Bedford, MA Veterans Affairs Medical Center. Drs. Volkman, Luger, Hogan, Shimada, Mclnnes, Feng, Houston, and Ms. Harvey, and Mr. Amante's efforts were supported in part by the Department of Veterans Affairs, Veterans Health Administration, Office of Research and Development. The views expressed in this article are those of the authors and do not necessarily reflect the position or policy of the Department of Veterans Affairs or the United States government. A subset of these analyses was presented at the Society of Behavioral Medicine Annual Meeting, March 2013.

\section{Author details}

1eHealth Quality Enhancement Research Initiative, US Department of Veterans Affairs, 200 Springs Road, Bedford, MA 01730, USA. ²University of Massachusetts Medical School, 368 Plantation Street, Worcester, MA 01605, USA. ${ }^{3}$ Department of Health Policy and Management, Boston University School of Public Health, 715 Albany Street Talbot Building, T2W, Boston, MA 02118, USA.

Received: 30 December 2013 Accepted: 3 June 2014 Published: 6 June 2014

\section{References}

1. Committee on Quality of Health Care in America, I.o.M: Crossing the quality chasm. Washington, DC: National Academy Press; 2001.

2. Hou J, Shim M: The role of provider-patient communication and trust in online sources in internet use for health-related activities. $J$ Health Commun 2010, 15(Suppl 3):186-199.

3. Joosten $E$, de Weert GH, van der Staak CPF, de Jong CAJ: Effect of shared decision-making on therapeutic alliance in addiction health care. Patient Prefer Adherence 2008, 2:277-285.

4. Joosten EA, DeFuentes-Merillas $L$, de Weert GHST, Sensky T, van der Staak CP, de Jong CA: Systematic review of the effects of shared decision-making on patient satisfaction, treatment adherence and health status. Psychother Psychosom 2008, 77(4):219-226.

5. Eysenbach G, Diepgen TL: The role of e-health and consumer health informatics for evidence-based patient choice in the 21st century. Clin Dermatol 2001, 19(1):11-17.

6. Cutilli CC: Seeking health information: what sources do your patients use? Orthop Nurs 2010, 29(3):214-219.

7. Wagner E: Chronic disease management: what will it take to improve care for chronic illness? Eff Clin Pract 1998, 1(1):2-4.

8. Fox SD, Duggan M: Health online 2013. Washington DC: Pew Internet and American Life Project; 2013. 
9. Lorence $\mathrm{D}$, Park H: Web-based consumer health information: public access, digital division, and remainders. MedGenMed 2006, 8(2):4.

10. Lorence DP, Park H, Fox S: Assessing health consumerism on the web: a demographic profile of information-seeking behaviors. J Med Syst 2006, 30(4):251-258.

11. Lorence DP, Park H, Fox S: Racial disparities in health information access: resilience of the digital divide. J Med Syst 2006, 30(4):241-249.

12. Hesse BW, Nelson DE, Kreps CL, Croyle RT, Arora NK, Rimer BK, Viswanath K Trust and sources of health information: the impact of the Internet and its implications for health care providers: findings from the first health information national trends survey. Arch Intern Med 2005, 165(22):2618-2624.

13. Currie K, Rajendran M, Spink J, Carter M, Anderson J: Consumer health information. What the research is telling us. Aust Fam Physician 2001 30(11):1108-1112.

14. Spink A, Cole C: Information and poverty: information-seeking channels used by African American low-income households. Library Information Science Research 2001, 23(1):45-65.

15. Cornwell B, Laumann EO, Schumm LP: The social connectedness of older adults: a national profile*. Am Sociol Rev 2008, 73(2):185-203.

16. Health information national trends survey. 2013. Available from: hints.cancer.gov.

17. Institute, N.C: HINTS: Helath Information National Trends Survey (HINTS 2005) final report; 2005

18. Nelson DE, Kreps GL, Hesse BW, Croyle RT, Willis G, Arora NK, Rimer BK, Viswanath KV, Weinstein N, Alden S: The Health Information National Trends Survey (HINTS): development, design, and dissemination. $J$ Health Commun 2004, 9(5):443-460. discussion 81-4.

19. LaRose R, Gregg J, Strover S, Strubhaar J, Carpenter S: Closing the rural broadband gap: promoting adoption of the internet in rural America. Telecommun Policy 2007, 6:359-373.

20. Sadasivam RS, Kinney RL, Lemon SC, Shimada SL, Allison JJ, Houston TK: Internet health information seeking is a team sport: analysis of the pew internet survey. Int J Med Inform 2013, 82(3):193-200.

21. Arora NK, McHorney CA: Patient preferences for medical decision making: who really wants to participate? Med Care 2000, 38(3):335-341.

22. Wolff JL, Starfield B, Anderson G: Prevalence, expenditures, and complications of multiple chronic conditions in the elderly. Arch Intern Med 2002, 162(20):2269-2276.

23. Matsuyama RK, Wilson-Genderson M, Kuhn L, Moghanaki D, Vachhani $H$, Paasche-Orlow M: Education level, not health literacy, associated with information needs for patients with cancer. Patient Educ Couns 2011, 85(3):e229-e236.

24. Nielsen-Bohlman L, Panzer A, Kindig DA: Health literacy: a prescription to end confusion. Washington DC: National Academies Press; 2004.

25. Billek-Sawhney B, Reicherter E: Literacy and the older adult: educational considerations for health professionals. Topics in Geriatric Rehabilitation 2005, 21(4):275-281.

26. Nutbeam D: The evolving concept of health literacy. Soc Sci Med 2008, 67(12):2072-2078

27. Eysenbach G, Powell J, Kuss O, Sa ER: Empirical studies assessing the quality of health information for consumers on the world wide web: a systematic review. JAMA 2002, 287(20):2691-2700.

28. Cline RJ, Haynes KM: Consumer health information seeking on the internet: the state of the art. Health Educ Res 2001, 16(6):671-692.

29. Finney Rutten $L$, Davis T, Beckjord EB, Blake K, Moser RP, Hesse BW: Picking up the pace: changes in method and frame for the health information national trends survey (2011-2014). J Health Commun 2012, 17(8):979-989.

30. Patient protection and affordable care act, Public Law; 2010:111-148.

31. Klem M, Saghafi E, Abromitis R, Stover A, Dew MA, Pilkonis P: Building PROMIS item banks: librarians as co-investigators. Qual Life Res 2009 18(7):881-888.

32. Levinson W, Lesser CS, Epstein RM: Developing physician communication skills for patient-centered care. Health Aff (Millwood) 2010, 29(7):1310-1318.

doi:10.1186/1471-2296-15-111

Cite this article as: Volkman et al:: The National Cancer Institute's Health Information National Trends Survey [HINTS]: a national cross-sectional analysis of talking to your doctor and other healthcare providers for health information. BMC Family Practice 2014 15:111.

\section{Submit your next manuscript to BioMed Central and take full advantage of:}

- Convenient online submission

- Thorough peer review

- No space constraints or color figure charges

- Immediate publication on acceptance

- Inclusion in PubMed, CAS, Scopus and Google Scholar

- Research which is freely available for redistribution 